\title{
Dietary fibre in infancy and childhood
}

\author{
C. A. Edwards* and A. M. Parrett \\ Department of Human Nutrition, Glasgow University, Yorkhill Hospitals, Glasgow G3 8SJ
}

\begin{abstract}
There is very little evidence for the effects of dietary fibre in young children and current dietary guidelines are based on assumptions and data extrapolated from studies in adults. The first years of life may be critical for the establishment of a healthy colonic microflora, as well as good eating habits. The lack of clear and well-founded guidelines for the intake of dietary fibre in childhood may hinder both factors. The fears that a high-fibre diet in children $<5$ years of age will lead to growth faltering and mineral imbalance are not well supported in the literature, especially for children in the developed world. Indeed, with the rising levels of obesity, fibre intake may be of benefit in reducing energy intake. A low-fibre diet may also be implicated in the aetiology of childhood constipation and appendicitis. The latest proposals for the definition of dietary fibre include oligosaccharides, which may act as prebiotics. There are potential health benefits of including oligosaccharides in the diets of infants and children, but more research is needed to consider the long-term effects. The immature intestine of the infant may also result in a greater amount of starch entering the colon during weaning, and this starch would now be considered dietary fibre under the new definitions. Much new research is needed to allow adequate recommendations for the intake of dietary fibre in childhood based on data collected in appropriate age-groups.
\end{abstract}

\section{Dietary fibre: Childhood: Microflora: Fermentation}

There is very little information available about the effects of dietary fibre in infancy and childhood. This situation has led to the recommendations for daily fibre intake in these age-groups to be based on guesswork, caution and extrapolation of data from adults. In the UK recommendations are very vague. The UK recommended dietary values for children state that fibre intake should be proportionately lower than that of adults, related to body size and that children $<2$ years of age should not be given such foods (dietary fibre-containing) at the expense of energy-rich foods (Department of Health, 1991). In the USA the suggested levels are age (years) + $5 \mathrm{~g} / \mathrm{d}$ (Dwyer 1995; Williams et al. 1995) and $0.5 \mathrm{~g} / \mathrm{kg}$ (Committee on Nutrition of the American Academy of Pediatrics, 1998).

There have been fears that a diet too high in dietary fibre may lead to growth retardation and malabsorption of minerals (Department of Health, 1991). However, there is very little evidence that this situation exists in the developed world, and with the growing risk of obesity in children a fibre-rich diet that reduces energy intake may be of great benefit (Kimm, 1995). Moreover, good eating habits are developed early and in many countries adult fibre intakes are too low.
It is important that the amount of dietary fibre recommended for young children is based on good information obtained in the age-groups concerned. As these data are lacking, the present review will consider the current state of our knowledge of non-digestible carbohydrates in infancy and childhood. In addition, as new definitions of dietary fibre increase the range of carbohydrates identified as dietary fibre (Anon, 2001), and include more foods whose lack of digestibility depends on the physiology of the individual, a new approach must be taken to evaluate the likely benefits and adverse effects of these carbohydrates in children, who may have a different response from adults.

\section{Dietary fibre sources in infancy and childhood}

In the last 5 years the debate over the definition of dietary fibre has been renewed in light of the interest in nonabsorbable carbohydrates not previously considered as dietary fibre. The proposed new definition covers a whole range of carbohydrates, other than NSP, such as resistant starch, fructo-oligosaccharides, galacto-oligosaccharides and some synthetic non-absorbable carbohydrates (Anon, 
2001). These carbohydrates may be of special importance in very young children and have not previously been thought of as sources of dietary fibre, and therefore have not been considered in recommendations. In addition, the lack of complete absorption of some sugars, such as lactose and fructose, may add to the carbohydrate load in infancy (Kneepkens et al. 1984) and in early childhood, and this factor must be taken into account when making dietary recommendations.

At birth the functions of the pancreas and gut are not fully matured and carbohydrate, which is readily digested and absorbed in the small intestine of adults, may escape into the colon of infants (Christian et al. 1999). Starch digestion in the small intestine is reduced and faecal starch is detected in infants up to the age of 3 years (Verity \& Edwards 1994; Parrett et al. 2000). A marked amount of lactose escapes into the large intestine and, in addition, human milk contains a wide range of non-absorbable oligosaccharides (approximately $12 \mathrm{~g} / \mathrm{l}$; Kunz et al. 2000), which will be available for fermentation in the colon. Thus, human milk could, if the new definitions are accepted, be considered the first source of dietary fibre. Other early sources of non-digestible carbohydrates include thickeners in medicines and anti-regurgitation products (Aggett et al. 2003).

At weaning new complex carbohydrate foods are included in the diet. For the first time the colonic flora encounter cellwall polysaccharides, and the bacteria must develop the ability to cope with them. The increase in starch intake with a still-immature digestive function will provide an additional source of fermentable material (Christian et al. 1999) in the large intestine, and other carbohydrates such as fructose from fruit juices may also escape absorption (Kneepkens et al. 1984; Lifshitz et al. 1992). Commercial weaning foods vary considerably in their fibre content; some foods contain very little, but other foods, mainly vegetable-containing foods, contain approximately $20 \mathrm{~g} / \mathrm{kg}$ wet weight, and muesli and cereal-based weaning foods may contain $>30 \mathrm{~g} / \mathrm{kg}$.

The main sources for NSP of 1.5-4.5-year-old children in the National Diet and Nutrition Survey in the UK (Gregory et al. 1995) were cereal products (43\%), vegetables, potatoes and savoury snacks $(35 \%)$ and fruits $(12 \%)$. The mean total intakes of NSP were $5.5 \mathrm{~g} \mathrm{NSP/d}$ at $1.5-2.5$ years, and $6.2 \mathrm{~g} / \mathrm{d}$ at $2.5-3.5$ years. Between 3.5 and 4.5 years boys ate $6.8 \mathrm{~g} / \mathrm{d}$ whereas girls ingested $6.4 \mathrm{~g} / \mathrm{d}$. However, the values for individuals varied from 2 to $12 \mathrm{~g} / \mathrm{d}$. In older children (Gregory et al. 2000) the NSP intake rose from $9.1 \mathrm{~g} / \mathrm{d}$ at $4-6$ years to $13.3 \mathrm{~g} / \mathrm{d}$ at $15-18$ years for boys and from $8 \cdot 0-10 \cdot 6 \mathrm{~g} / \mathrm{d}$ for girls at the same ages. Again, cereals and cereal products provided $>40 \%$ of the NSP, approximately $40 \%$ was provided by vegetables, potatoes and cereal snacks, approximately $17 \%$ came from vegetables and $10 \%$ from roast or fried potatoes and chips. At 4-6 years old, $10 \%$ of NSP was derived from fruits and nuts but this contribution fell with age to $5 \%$ in boys and $7 \%$ in girls by $15-18$ years (Gregory et al. 2000).

\section{Fibre and the colonic microflora}

To fully understand the likely physiological effects of dietary fibre in childhood, it is important to understand the development of the gastrointestinal tract, and most importantly the development of the gut microflora. The actions of dietary fibre are greatly influenced by the extent to which they are fermented by the colonic bacteria. Fermentation reduces the impact of dietary fibre on stool output. Moreover, the short-chain fatty acids (SCFA) produced during fermentation may have important health benefits, as well as acting as an energy source (Livesey, 1990). The supply of fermentable substrates to the colon may influence the balance of the microflora, and if the flora that is established early is maintained in the long term after gut barrier functions have matured, then early diet may be of major influence beyond infancy.

\section{Bacterial colonisation of the human intestine in infancy}

In adults the colon has a complex and relatively stable bacterial ecosystem composed of bacteroides, bifidobacteria, eubacteria, lactobacilli and smaller numbers of clostridia, enterobacteria and streptococci. Until recently it had been estimated that there were more than 400 species in the dominant flora (Moore \& Holdeman, 1974); however, new techniques, which measure rRNA or DNA (Doré et al. 1998; Harmsen et al. 1999; Vaughan et al. 2000), have suggested that up to $80 \%$ of the bacterial RNA in faeces is not accounted for by known bacteria.

The colonic flora develops from birth, and the initial stages of colonisation may be important not only for the health of the infant but also for establishing the flora of the adult, which may then have an impact on health in later life. It is thought that there are two critical stages in the colonisation of the infant gut: (1) shortly after birth; (2) during weaning.

Many factors, including the environment, genetics, gestational age (pre-term or term), mode of delivery (vaginal or Caesarean; Grönlund et al. 1999) and type of feeding (breast-fed or formula-fed; Long \& Swenson 1977; Tannock et al. 1990; Edwards et al. 1994), have been reported to influence the colonisation of the neonatal gut. The exact role of each factor is difficult to investigate in isolation in vivo.

At birth the infant colon is sterile, but is rapidly colonised after birth by microbes both from the mother and the environment (Zetterstrom et al. 1994). The bacteria in the gastric content of babies 5-10 min after birth has been shown to be similar to those near the mother's cervix (Brook et al. 1979). At $12 \mathrm{~h}$ after birth the dominant bacterial species in the meconium are facultative anaerobes such as Enterobacteriaceae and streptococci (Schmitz \& McNeish, 1987). These bacteria grow rapidly in numbers up until $24 \mathrm{~h}$. During this time other bacteria bifidobacteria, bacteroides and clostridia are also found in the infant's gut.

Early diet has a major influence on the colonisation process. In breast-fed infants the facultative anaerobes create a reduced environment that promotes the growth of bifidobacteria; simultaneously the facultative anaerobes decrease in number. In contrast, whilst bifidobacteria increase in formula-fed infants, there is no corresponding decrease in facultative anaerobes. As a result the formulafed infant has a more diverse bacterial profile, which is more like that of an adult (Schmitz \& McNeish, 1987). The 
introduction of solid food to the breast-fed infant produces major changes in the microflora. The high buffering capacity of meals makes the colonic contents less acidic, thereby allowing growth of enterobacteria, enterococci, bacteroides, clostridia and streptococci (Stark \& Lee, 1982). In formula-fed infants, changes are less dramatic; counts of facultative anaerobes remain high whilst there is continued colonisation of anaerobes other than bifidobacteria. At approximately 12 months the flora of all infants begins to resemble that of adults.

Some recent studies investigating the development of the microflora using the new molecular techniques have confirmed the major differences between breast-fed and formula-fed infants (Harmsen et al. 2000; Martin et al. 2000). However, they have also shown that both groups have a flora that diversifies in the first few months of life, and this diversification starts before weaning commences (Martin et al. 2000). One study did not find such a major difference between the diversity of breast-fed and formula-fed infants at 1 month using $16 \mathrm{~S}$ rDNA analysis and denaturing gradient gel electrophoresis (Satokari et al. 2002). More work is needed using these new techniques to fully understand the colonisation process.

\section{Maturation of colonic bacterial metabolism in infancy}

Although it is important to establish the succession of bacterial species in the colonisation process, it is necessary to know how the flora may respond to non-digestible carbohydrates. It is important to understand the development of the metabolic abilities of the flora as these activities reflect the flora as a whole, and each particular function may be performed by more than one species or group.

The colonic flora of the adult colon has a wide range of possible metabolic activities. Many of these activities are not developed in the simpler microflora of the infant (Midtvedt et al. 1988, 1994; Midtvedt \& Midtvedt, 1992, 1993).

The production of SCFA from the fermentation of carbohydrate is established very early, but the profile of SCFA differs greatly between adults and infants. In meconium, SCFA concentrations are very low, only about $10 \%$ of the adult values. They increase markedly in the first $4 \mathrm{~d}$ of life; however, the proportions of individual SCFA depend on the mode of feeding. There is a higher proportion of acetate and lactate in the faeces of infants, and butyrate production, which is thought to be important in adults, is very low; acetate:propionate:butyrate:other acids at $4 \mathrm{~d}$ was found to be 89:5:5:1 in infants (Szylit \& Andrieux, 1993). This ratio probably reflects not only differences in flora but also differences in carbohydrates available for fermentation. The primary carbohydrate source for the colonic flora of neonates is lactose and this factor may account for the high proportion of acetate. The profiles of SCFA depend on whether the child is breast-fed or formula-fed. The breastfed infant with predominantly bifidobacteria and lactobacilli produces mainly acetic acid and lactic acid (Edwards et al. 1994). In contrast, the more diverse flora of the formula-fed infant produces mainly acetic acid and propionic acid, with a small amount of butyric acid and little or no lactic acid. The concentrations and profiles of SCFA in infant faeces change as weaning progresses (Midtvedt \& Midtvedt, 1992; Parrett, 2001). In breast-fed infants propionic acid concentration increases as weaning commences and butyric acid increases later in weaning as lactic acid concentration falls. In formula-fed infants, who already have higher propionic acid before weaning, the main change is an increase in butyric acid concentration (Parrett, 2001).

Other bacterial activities are also slow to develop. The ability to convert bilirubin to urobilinogen follows the development of SCFA production, but at 6 months the average value of urobilinogen was still only about one-tenth of values found in adults. In four of the subjects urobilinogen production was absent (Midtvedt et al. 1988). In a similar study it was absent in one of ten children at 2 years of age (Norin et al. 1985).

Mucin degradation ability is also slow to develop (Norin et al. 1985). In very young infants (up to $5 \mathrm{~d}$ of age) a germ-free animal characteristic pattern of mucin was seen. Microbial mucin degradation did not occur. In older infants twenty of forty-six samples from twenty-three infants aged 2-11 months and in all samples of children $>20$ months there was a shift to the type of mucin degradation products seen with an adult-like microflora or that of microfloraassociated animals. The establishment of a mucin-degrading flora occurred at approximately 3 months of age (Midtvedt et al. 1988, 1994). The ability to deconjugate bile acids was already present at 1 month (Jonsson et al. 1995), whereas the ability to convert cholesterol to coprostanol developed in the second half of the first year and was delayed by breast-feeding (Midtvedt \& Midtvedt, 1993). Thus, the development of a fully functional active flora is a slow process, but the maturation of the system varies. Some activities are almost fully established before others start to develop; this situation must be related to the colonisation process and the changing dominance of groups of bacteria with these metabolic abilities.

\section{Development of fermentation capacity in infancy and childhood}

Before non-digestible carbohydrates are increased in the diet it is important that the ability of the colonic flora to ferment them is explored. This ability will affect the impact of the carbohydrate on stool output and also on faecal energy losses.

Before weaning breast-fed infants ingest only human milk, but a sizeable amount of carbohydrate, lactose and fructo-oligosaccharides may still escape digestion and absorption because of the immature activity of pancreatic and brush-border enzymes (McClean \& Weaver, 1993). As weaning begins infants are exposed for the first time to a number of complex carbohydrates. A sizeable amount of starch will escape digestion because of the lack of chewing ability and immature pancreatic amylase in these infants (McClean \& Weaver, 1993). This starch and any ingested dietary fibre will enter the colon, where it is available for fermentation by the bacteria. If colonic fermentation capacity develops rapidly, the colonic salvage of energy may contribute substantially to daily energy needs, up to $8.4 \mathrm{~kJ}$ (2 kcal)/g unabsorbable carbohydrate (Livesey, 1990) in these infants. If colonic fermentation capacity is restricted 
the unabsorbed and unfermented carbohydrate is likely to increase stool output and faecal energy losses.

When the fermentation capacity of the faecal flora from breast-fed and formula-fed infants for simple and complex carbohydrates was compared with that of adult faecal flora using a simple in vitro model, the infant flora from both groups of infants was much less able to ferment complex carbohydrates (Parrett \& Edwards, 1997a) than the adult flora. The total amount of SCFA produced by the infants was not affected by the type of milk fed, but the proportions of individual SCFA reflected the different patterns seen in infant faeces (Parrett \& Edwards, 1997a).

After weaning the colonic flora of the formula-fed infant developed the ability to ferment complex carbohydrates more quickly than that of the breast-fed infant. This difference is understandable in light of the greater diversity of species in the formula-fed infant colon and the greater populations of Gram-negative anaerobes. In a crosssectional in vitro study of fermentation capacity of infants at different stages of weaning (Parrett et al. 1997), breast-fed infants could ferment simple sugars, lactose and glucose well before weaning. However, fructo-oligosaccharide was less well fermented and soyabean polysaccharide underwent minimal fermentation. In early weaning ( 1 month after introduction of solid foods) the ability to ferment raftilose increased, but the ability to ferment complex carbohydrates did not increase until late weaning ( 7 months -1 year). There was no significant difference in fermentation capacity of the formula-fed infants at different stages of weaning, indicating a faster maturation of their colonic flora (Parrett \& Edwards, 1997b). In a more recent longitudinal study breast-fed infants had a similar slow development of the capacity to ferment complex carbohydrate (AM Parrett and CA Edwards, unpublished results), but the ability to ferment pectin increased at an earlier age than the ability to ferment resistant starch and other complex carbohydrates. In another study using similar in vitro methods, however, weaned infants appeared to have a more rapid fermentation of starch than adults, perhaps reflecting the greater likelihood of starch entering the colon of the infants (Christian et al. 2000). The slow development of the digestive and fermentation capacity of infants was also demonstrated by the excretion of starch in faeces of children up to 3 years of age (Verity \& Edwards, 1994; Parrett et al. 2000). However, the impact on faecal energy losses would be very low. In the developing world, where preschool children eat starchy foods, such as cassava, with low digestibility, faecal starch is high and may be a cause of high faecal energy losses (Hamaker et al. 1991). Studies in the rat have shown that the introduction of a particular fibre in weaning foods may also have a longer-term impact on fermentation capacity for the same fibre in later life (Armstrong et al. 1992).

\section{Potential actions of dietary fibre in infancy and childhood}

\section{Mineral balance}

The great concern about recommending a high-fibre diet for children is that it will decrease the energy density of the diet and cause problems for growth. Secondary to this factor is the concern that the fibre may trap micronutrients within the gut and therefore reduce bioavailability at a time when demands are high. In adults it has been well established that a high-fibre diet has very little impact on mineral balance, but there have been almost no studies in children. However, several animal studies have demonstrated that an increased intake of fermentable material increases the amount of Ca absorbed in the large intestine (Lopez et al. 1998; Scholz-Ahrens et al. 2001; Younes et al. 2001). This increase may be due to the release of trapped $\mathrm{Ca}$ from the fermented material and the low colonic $\mathrm{pH}$.

\section{Impact on growth}

There are little data on the effects of dietary fibre in children $<2$ years of age. With the rapid growth of infants it is thought that dietary fibre would have a major effect on growth by reducing energy intake. However, this potential effect has yet to be established. A previous study (Shull et al. 1977) of vegetarian children did find lower growth velocities in children $<2$ years, but this finding may have been related to delayed weaning or the lack of meat, rather than the dietary fibre content of the diet. Vegan children are reported to be shorter than normal controls, but this outcome may not be related to dietary fibre intake (Sanders, 1988). There have been other reports of growth delay in 'vegetarian' children, and children on macrobiotic diets (Dwyer et al. 1983), but it is difficult to assess these results for the impact of the influence of dietary fibre, as these diets have many other variations from normal diets.

The impact of dietary fibre on growth may be more apparent at a time of rapid growth, such as in the growth spurt seen before puberty. A study of the effect of a high-fibre, low-fat diet on 136 Scottish schoolchildren aged 7-8 years found little effect of the high-fibre diet on growth (Ruxton et al. 1995). The children on a high-NSP diet had mean height, weight, height velocity and BMI that were similar to those of children on a lower-fibre diet. There were no associations between growth and the higher intake of fibre.

In a group of 445 native Canadian children (2-19 years) with high risk of obesity (Hanley et al. 2000), fibre consumption was associated with a reduced risk of overweight. For each $0.77 \mathrm{~g} / \mathrm{MJ}$ increase in fibre consumption in the previous $24 \mathrm{~h}$ of the study day there was a 1.4-fold decrease in risk of overweight. There was no relationship with other macronutrients.

\section{Constipation and appendicitis}

There have been several studies that have considered the role of low-fibre diets in the aetiology of childhood constipation. A low-fibre diet may be an important factor in the development of chronic constipation (Morais et al. 1999). In a case-control study of Greek children aged 2-14 years 291 children with constipation were compared with 1602 controls (Roma et al. 1999). It was shown that children with constipation have lower energy and nutrient intakes, and dietary fibre alone was independently negatively correlated with constipation, with no relationship with age and the age of onset of the chronic constipation. 
In a recent study in Brazil (de Araujo \& Calcado, 1999) it was found that $28 \%$ of 8 -10-year-old children studied (n 391) whose fibre intake ranged from 3.4 to $4.8 \mathrm{~g} / \mathrm{d}$ had constipation. However, other studies have not found a strong association between dietary fibre and constipation (Guimaraes et al. 2001).

In another Greek study (Adamidis et al. 2000) 203 children with histologically-established appendicitis were compared with 1922 controls. The children with appendicitis had a lower fibre intake than the controls $(17.4 \mathrm{~g} / \mathrm{d} v$. $20.4 \mathrm{~g} / \mathrm{d}$ ). The patients were much more likely to have had a history of chronic constipation than the controls.

One problem of neglecting the role of dietary fibre in childhood is the tendency to omit fibre in clinical feeds for children and to use laxatives in children with reduced mobility. Children with severe developmental disabilities (3-17 years) were able to decrease the use of laxatives by increasing their fibre intake to $17 \mathrm{~g} / \mathrm{d}$ (Tse et al. 2000). The baseline intake of fibre for these children had been $2 \mathrm{~g} / \mathrm{d}$.

\section{Prebiotics}

The new proposed definition of dietary fibre will include oligosaccharides, which have been shown to have prebiotic effects, i.e. they increase the growth of lactic acid bacteria, and in particular bifidobacteria. These bacteria are similar to the organisms used as probiotics. Probiotic organisms have been shown to reduce the incidence of diarrhoea and reduce the incidence of eczema in young children (Pathmakanthan et al. 2000; Isolauri 2001). Several differences have been identified between the gut flora of infants with allergy and those with no allergy, and between populations with high risk of allergy and those with low risk (Bjorksten et al. 1999; Kalliomaki et al. 2001). These differences included the levels and species of bifidobacteria (Ouwehand et al. 2001) and lactobacilli as well as the metabolic products such as isocaproic acid, which is higher in those with allergy (Bottcher et al. 2000).

The action of prebiotics in promoting the growth of lactic acid bacteria suggests that they could be beneficial in infancy in the same way as probiotics. However, there have been insufficient studies to establish their benefits. It has been shown that adding a prebiotic mixture of oligosaccharides to infant formula can increase the survival of bifidobacteria in the gut (Moro et al. 2002), but as yet there have been no reports that show a major health benefit. Excessive fructose and sorbitol in the colon has been associated with abdominal pain and diarrhoea (Hyams, 1982; Kneepkens et al. 1984; Lifshitz et al. 1992). More research is needed in this area.

\section{Conclusion}

There is very little evidence that dietary fibre in the diet of children in the developed world is harmful. Indeed, with the growing rate of childhood obesity a reduction in the energy density of the diet may be of great benefit. The new proposed definition for dietary fibre includes many compounds such as resistant starch and oligosaccharides that may be of more benefit to young children. The gut microflora of the infant develops slowly and in response to diet. It is necessary to understand the implications for the microflora of increasing fermentable components in the diet of the young, and any long-term effects. Much more research is needed before it will be possible to make dietary recommendations for dietary fibre intake at the critical stages of infancy and childhood. These recommendations should be based on data collected for the appropriate age-groups.

\section{References}

Adamidis D, Roma-Giannikou E, Karamolegou K, Tselalidou E \& Constantopoulos A (2000) Fiber intake and childhood appendicitis. International Journal of Food Science and Nutrition 51, $153-157$.

Aggett PJ, Agostoni C, Axelsson I, Edwards CA, Goulet O, Hernell O, Koletzko B, Lafeber HN, Michaelsen KF, Micheli J-L, Rigo J, Szajewska H \& Weaver LT (2003) Non-digestible carbohydrates in the diets of infants and young children - Comment by ESPGHAN Committee on Nutrition. Journal of Pediatric Gastroenterology and Nutrition (In the Press).

Anon (2001) The definition of dietary fibre. Report of the Dietary Fiber Definition Committee of the American Association of Cereal Chemists. Cereal Food World 46, 112-129.

Armstrong EF, Eastwood MA, Edwards CA, Brydon WG \& MacIntyre CCA (1992) The effect of weaning diet on the subsequent colonic metabolism of dietary fibre in the adult rat. British Journal of Nutrition 68, 741-751.

Bjorksten B, Naaber P, Sepp E \& Mikelsaar M (1999) The intestinal microflora in allergic Estonian and Swedish 2 year old children. Clinical and Experimental Allergy 29, 342-346.

Bottcher MF, Norin EK, Sandin A, Midtvedt T \& Bjorksten B (2000) Microflora associated characteristics in faeces from allergic and non-allergic infants. Clinical and Experimental Allergy 30, 1590-1596.

Brook I, Barett C, Brinkman C, Martin W \& Finegold S (1979) Aerobic and anaerobic bacterial flora of the maternal cervix and newborn gastric fluid and conjunctiva: a prospective study. Pediatrics 63, 451-454.

Christian M, Edwards CA \& Weaver LT (1999) Starch digestion in infancy. Journal of Pediatric Gastroenterology and Nutrition 29, 116-124.

Christian MT, Edwards CA, Preston T, Johnson LA, Varley R \& Weaver LT (2000) Patterns of colonic starch fermentation from infancy to adulthood. Proceedings of the Nutrition Society 59, 36A.

Committee on Nutrition of the American Academy of Pediatrics (1998) Carbohydrate and dietary fiber. Pediatric Nutrition Handbook, pp. 203-211. Elk Grove Village, IL: American Academy of Pediatrics.

de Araujo Santan Anna AM \& Calcado AC (1999) Constipation in school aged children at public school in Rio de Janeiro, Brazil. Journal of Pediatric Gastroenterology and Nutrition 29, 190-193.

Department of Health (1991) Dietary Reference Values for Food Energy and Nutrients for the United Kingdom. Report on Health and Social Subjects no 41. London: H.M. Stationery Office.

Doré J, Sghir A, Hannequart-Grramet G, Corthier G \& Pochart P (1998) Design and evaluation of a 16S rRNA-targeted oligonucleotide probe for specific detection and quantitation of human faecal Bacteroides populations. Systematic and Applied Microbiology 21, 65-71.

Dwyer JT (1995) Dietary fiber for children, how much? Pediatrics 96, 1019-1022.

Dwyer JT, Andrew EM, Berkey C, Valadian I \& Reed RB (1983) Growth in 'new' vegetarian preschool children using the Jenss- 
Bayley curve fitting technique. American Journal of Clinical Nutrition 37, 815-827.

Edwards CA, Parrett AM, Balmer SE \& Wharton BA (1994) Faecal short chain fatty acids in breast fed and formula fed babies. Acta Paediatrica 83, 459-462.

Gregory JR, Collins DL, Davies PSW, Hughes JM \& Clarke PC (1995) National Diet and Nutrition Survey of Children Aged $1^{1 / 2}-4^{1 / 2}$ Years. London: H.M. Stationery Office.

Gregory J, Lowe S, Bates CJ, Prentice A, Jackson LV, Smithers G, Wenlock R \& Farron M (2000) National Diet and Nutrition Survey of Young People Aged 4-18 Years. London: H.M. Stationery Office.

Grönlund M-M, Lehtonen O-P, Eerola E \& Keeo P (1999) Fecal microflora in healthy infants born by different methods of delivery: permanent changes in intestinal microflora after cesarean delivery. Journal of Pediatric Gastroenterology and Nutrition 28, 19-25.

Guimaraes EV, Goulart EM \& Penna FJ (2001) Dietary fiber intake, stool frequency and colonic transit time in chronic functional constipation in children. Brazilian Journal of Medical and Biological Research 34, 1147-1153.

Hamaker BR, Rivera K, Morales E \& Graham GG (1991) Effects of dietary fiber and starch on faecal composition in preschool children consuming maize amaranth or cassava flours. Journal of Pediatric Gastroenterology and Nutrition 13, 59-66.

Hanley AJ, Harris SB, Gittelsohn J, Wolever TM, Saksvig B \& Zinman B (2000) Overweight among children and adolescents in a native Canadian community: prevalence and associated factors. American Journal of Clinical Nutrition 71, 693-700.

Harmsen HJM, Elfferich P, Schut F \& Welling GW (1999) A 16S rRNA-targeted probe for the detection of lactobacilli and enterococci in faecal samples by fluorescent in situ hybridisation. Microbial Ecology in Health and Disease 11, 3-12.

Harmsen HJM, Wibleboer-Veloo ACM, Raangs GC, Wagendorp AA, Klijn N, Bindels JG \& Wellings GW (2000) Analysis of intestinal flora development in breast-fed and formula-fed infants using molecular identification and detection methods. Journal of Pediatric Gastroenterology and Nutrition 30, 61-67.

Hyams JS (1982) Chronic abdominal pain caused by sorbitol malabsorption. Journal of Pediatrics 100, 772-773.

Isolauri E (2001) Probiotics in the prevention and treatment of allergic disease. Pediatric Allergy and Immunology 12, Suppl. $14,56-59$.

Jonsson G, Midtvedt AC, Norman A \& Midtvedt T (1995) Intestinal microbial bile acid transformation in healthy children. Journal of Pediatric Gastroenterology and Nutrition 20, 394-402.

Kalliomaki M, Kirjavainen P, Eerola E, Kero P, Salminen S \& Esolauri E (2001) Distinct patterns of neonatal gut microflora in infants in whom atopy was and was not developing. Journal of Allergy and Clinical Immunology 107, 129-134.

Kimm SY (1995) The role of dietary fibre in the development and treatment of childhood obesity. Pediatrics 96, 1010-1014.

Kneepkens CMF, Vonk RJ \& Fernandes S (1984) Incomplete intestinal absorption of fructose. Archives of Disease in Childhood 59, 735-738.

Kunz C, Rudloff S, Baier W, Klein N \& Strobel S (2000) Oligosaccharides in human milk: structural, functional and metabolic aspects. Annual Review of Nutrition 20, 699-722.

Lifshitz F, Ament ME, Kleinman RE, Klish W, Lebenthal E, Perman J \& Udall JN (1992) Role of juice carbohydrate malabsorption in chronic non-specific diarrhoea in children. Journal of Pediatrics 120, 825-829.

Livesey G (1990) Energy values of unavailable carbohydrate and diets: an inquiry and analysis. American. Journal of Clinical Nutrition 51, 617-637.
Long SS \& Swenson RM (1977) Development of anaerobic faecal flora in healthy newborn infants. Journal of Pediatrics 91, 298-301.

Lopez HW, Coudray C, Bellanger J, Younes H, Demigne C \& Remesey C (1998) Intestinal fermentation lessens the inhibitory effects of phytic acid on mineral utilization in rats. Journal of Nutrition 128, 1192-1198.

McClean P \& Weaver LT (1993) Ontogeny of human pancreatic exocrine function. Archives of Disease in Childhood 68, 62-65.

Martin F, Savage SAH, Parrett AM, Gramet G, Dore J \& Edwards CA (2000) Investigation of bacterial colonisation of the colon in breast-fed infants using novel techniques. Proceedings of the Nutrition Society 59, 64A.

Midtvedt AC, Carlstedt-Duke B \& Midtvedt T (1994) Establishment of a mucin-degrading intestinal microflora in the first two years of human life. Journal of Pediatric Gastroenterology and Nutrition 18, 321-326.

Midtvedt AC, Carlstedt-Duke B, Norin KE, Saxerholt H \& Midtvedt T (1988) Development of five metabolic activities associated with the intestinal microflora of healthy infants. Journal of Pediatric Gastroenterology and Nutrition 7, 559-567.

Midtvedt AC \& Midtvedt T (1992) Production of short chain fatty acids by the intestinal microflora during the first two years of human life. Journal of Pediatric Gastroenterology and Nutrition 15, 395-403.

Midtvedt AC \& Midtvedt T (1993) Conversion of cholesterol to coprostanol by the intestinal microflora during the first two years of human life. Journal of Pediatric Gastroenterology and Nutrition 17, 161-168.

Moore WEC \& Holdeman LV (1974) Human fecal flora: The normal flora of 20 Japanese-Haiwaiians. Applied Microbiology 27, 961-979.

Morais MB, Vitolo MR, Aguirre AN \& Fagundes-Neto U (1999) Measurement of low dietary fibre intake as a risk factor for chronic constipation in children. Journal of Pediatric Gastroenterology and Nutrition 29, 132-135.

Moro G, Minoli I, Mosca M, Jelinek J, Stahl B \& Boehm G (2002) Dosage related bifidogenic effects of galacto and fructo oligo saccharides in formula fed term infants. Journal of Pediatric Gastroenterology and Nutrition 34, 291-295.

Norin KE, Gustafsson BE, Lindblad BS \& Midtvedt T (1985) The establishment of some microflora associated biochemical characteristics in feces from children during the first years of life. Acta Paediatrica Scandinavica 74, 207-212.

Ouwehand AC, Isolauri E, He F, Hashimoto H, Benno Y \& Salminen S (2001) Differences in Bifidobacterium flora composition in allergic healthy infants. Journal of Allergy and Clinical Immunology 108, 144-145.

Parrett AM (2001) Development of colonic fermentation in early life. $\mathrm{PhD}$ Thesis, University of Glasgow.

Parrett AM \& Edwards CA (1997a) In vitro fermentation of carbohydrate by breast fed and formula fed infants. Archives of Disease in Childhood 76, 249-253.

Parrett AM \& Edwards CA (1997b) The effect of weaning on fermentation capacity in formula fed infants. Proceedings of the Nutrition Society 56, 309A.

Parrett AM, Khanna S \& Edwards CA (2000) Excretion of faecal starch and fat in breast fed and formula fed infants during weaning. Proceedings of the Nutrition Society 59, 64A.

Parrett AM, Lokerse E \& Edwards CA (1997) Colonic fermentation in vitro: development during weaning in breast fed infants is slower for complex carbohydrates than for sugars. American Journal of Clinical Nutrition 65, 927-933.

Pathmakanthan S, Meance S \& Edwards CA (2000) Probiotics: A review of human studies to date and methodological approaches. Microbial Ecology in Health and Disease Suppl. 2, 10-30. 
Roma E, Adamidis D, Nikolara R, Constantopoulos A \& Messaritakis J (1999) Diet and chronic constipation in children: the role of fiber. Journal of Pediatric Gastroenterology and Nutrition 28, 169-174.

Ruxton CH, Kirk TR, Holmes MA \& Belton NR (1995) No adverse effects on growth seen in Scottish school children consuming either low fat diets or diets relatively high in non-starch polysaccharides. Health Bulletin 53, 398-401.

Satakori RM, Vaughan EE, Favier CF, Dore J, Edwards C \& de Vos WM (2002) Diversity of Bifidobacterium and Lactobacillus spp in breast fed and formula fed infants as assessed by 16S rDNA sequence differences. Microbial Ecology in Health and Disease 14, 97-105.

Sanders TA (1988) Growth and Development of British vegan children. American Journal of Clinical Nutrition 48, Suppl. 3, $822-825$.

Schmitz J \& McNeish AS (1987) Development of structure and function of the gastrointestinal tract: Relevance for weaning. In Weaning: Why, What and When? pp. 1-43 [A Ballabriga and J Rey, editors]. New York: Nestlé Nutrition, Vevey/Raven Press.

Scholz-Ahrens KE, Schaafsma G, van de Heuvel EG \& Schrezenmeir J (2001) Effects of prebiotics on mineral metabolism. American Journal of Clinical Nutrition 73, 459S-464S.

Shull MW, Reed RB, Valadian I, Palombo R, Thorns H \& Dwyer JT (1977) Velocities of growth in vegetarian pre-school children. Pediatrics 60, 410-417.

Stark PL \& Lee A (1982) The microbial ecology of the large bowel of breast-fed and formula-fed infants during the first year of life. Journal of Medical Microbiology 15, 189-203.
Szylit O \& Andrieux C (1993) Physiological and pathophysiological effects of carbohydrate fermentation. World Review of Nutrition and Dietetics 74, 88-122.

Tannock GW, Fuller R, Smith SL \& Hall MA (1990) Plasmid profiling of members of the family Enterobacteriaceae, lactobacilli, and bifidobacteria to study the transmission of bacteria from mother to infant. Journal of Clinical Microbiology 28, 1225-1228.

Tse PW, Leung SS, Chan T, Sien A \& Chan AK (2000) Dietary fibre intake and constipation in children with severe developmental disabilities. Journal of Paediatrics and Child Health 36, 236-239.

Vaughan EE, Schut F, Heilig HGHJ, Zoetendal EG, de Vos WM \& Akkermans ADL (2000) A molecular view of the intestinal ecosystem. Current Issues in Intestinal Microbiology 1, 1-12.

Verity K \& Edwards CA (1994) Resistant starch in young children. Proceedings of the Nutrition Society 53, 105A.

Williams CL, Bollella M \& Wynder EL (1995) A new recommendation for dietary fiber in childhood. Pediatrics 96, 985-988.

Younes H, Coudray C, Bellnager J, Demigne C, Rayssiguier Y \& Remesy C (2001) Effects of two fermentable carbohydrates (inulin and resistant starch) and their combination on calcium and magnesium balance in rats. British Journal of Nutrition 86, 479-485.

Zetterstrom R, Bennet R \& Nord K-E (1994) Early infant feeding and the microecology of the gut. Acta Paeditrica Japonica 36 , $562-571$. 